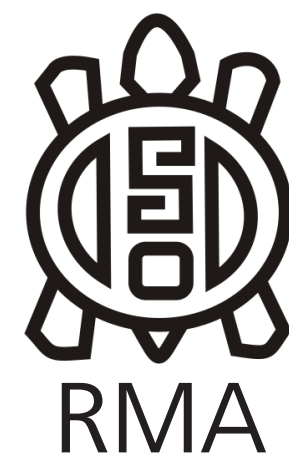

Dossier

Wichí: La gente

\title{
El intérprete wichí: derechos y desafíos
}

\author{
The wichi interpreter: rights and challenges
}

John Palmer*

\begin{abstract}
*Carrera de Comunicación Social, Facultad de Humanidades, Universidad Nacional de Salta (sede regional Tartagal). E-mail: watlahen@gmail.com
\end{abstract}

\begin{abstract}
Resumen
A pesar de diversas normativas (p. ej., la Constitución argentina) que establecen el derecho de los pueblos indígenas argentinos a contar con un intérprete bilingüe en sus gestiones judiciales y administrativas, en la realidad de los wichí (región del Gran Chaco) este derecho es por lo general desestimado. Su incumplimiento en los procesos judiciales, por ejemplo, es un defecto formal grave que amerita incluso la nulidad de lo actuado. Después de una breve contextualización sociolingüistica de la lengua wichí (familia mataguaya), se examina, por un lado, los derechos que asisten a los wichí de la Argentina a contar con un intérprete bilingüe en sus interacciones con el Estado y, por el otro, los diferentes obstáculos y desafíos que el intérprete wichí enfrenta en el desempeño de su tarea. Así pues, se comentan tres casos judiciales que muestran no sólo la complejidad del problema, sino también las ambigüedades e inconsistencias que conducen a una desatención del derecho a la legítima defensa y, en consecuencia, dañan moral y jurídicamente a los wichí. Además, para ejemplificar otra arista del problema, se analizan los letreros en wichí de la Ciudad Judicial de Tartagal (Salta) y una cartilla bilingüe sobre derecho indígena. Se concluye señalando que para los wichi el acto de interpretar y traducir implica un compromiso profundo con el "interior" de las palabras: una búsqueda previa de la buena voluntad wichí (husék) que hay o no hay en ellas, antes de verter lo expresado en una lengua a la otra lengua.
\end{abstract}

Palabras clave: Intérprete bilingüe; Justicia indígena; Traducción; Derechos lingüísticos.

\begin{abstract}
Despite various regulations (e. g., the Argentine Constitution) establishing the right of Argentina's indigenous peoples to have a bilingual interpreter in their judicial and administrative proceedings, in the real life of the Wichi people (Gran Chaco region) this right is generally disregarded. Non-compliance with this right in judicial proceedings, for example, is a serious formal defect that warrants the nullification of the act. After a brief sociolinguistic contextualization of the Wichi language (Mataguayan language family), this paper examines, on the one hand, the rights of the Wichi of Argentina to have a bilingual interpreter in their dealings with the State and, on the other hand, the different obstacles and challenges that Wichi interpreters face in carrying out their task. Thus, three judicial cases are commented upon in order to show not only the complexity of the problem, but also the ambiguities and inconsistencies that lead to a disregard for the right to legitimate defence and, therefore, harm the Wichi people, legally and morally. In addition, to illustrate another aspect of the problem, the Wichi signposts of the Tartagal Judiciary Centre (Salta) and a bilingual booklet on indigenous law are analyzed. The paper concludes that, for the Wichi, the act of interpreting and translating implies a deep commitment to the "inside" of words: a prior search for Wichi goodwill (husék) or its lack is required, before translating what is expressed in one language into the other.
\end{abstract}

Keywords: Bilingual interpreter; Indigenous justice; Translation; Linguistic rights.

Defensor Oficial: "¿Cuántos hijos tiene Ud?" Abuela wichí: "53"1

A modo de exordio, quizás no sea redundante contextualizar la lengua wichí a nivel continental. Sin contar aquéllas

\footnotetext{
${ }^{1}$ El epígrafe es la transcripción de parte de una entrevista que, en 2018, un Defensor Oficial de Tartagal mantuvo (sin intérprete) con la abuela materna de tres niñ@s wichí confinad@s en el Hogar de Niños local, cuya guarda ella peticionaba.
}

"silenciadas" por actos de genocidio o linguicidio -o por causas epidemiológicas- la UNICEF registra en América Latina un total de 420 lenguas indígenas "en uso" (Aasen, 2009, p. vii; Sichra, 2009, p. 13.). Sin embargo, la cifra es de valor relativo si se tiene en cuenta los criterios geográficos y sociolingüísticos en que la Organización basó su estudio:

i) Mesoamérica no se estableció como área de estudio, a pesar de las 81 lenguas precolombinas allí habladas, 
agrupadas en 9 familias lingüísticas ${ }^{2}$;

ii) Se incluyeron a los afrodescendientes de ciertos países de Centroamérica y a los cimarrones (esclavos africanos fugitivos) de las Guyanas y Suriname (Sichra, 2009, pp. 3-4.).

Las 420 lenguas identificadas y actualmente habladas (con un grado de vitalidad variable) se agrupan en 99 familias lingüísticas (Sichra, 2009, p. 13) ${ }^{3}$. Nuevamente, la cifra no es convincente, ya que más de la mitad (56) de las familias diferenciadas tienen un solo miembro o corresponden a "lenguas independientes" -con lo cual se desdibuja el concepto de "familia lingüística"4. Otro punto de desconcierto -sobre todo en el contexto del presente volumen- es que el cuadro al que se acaba de referir (n. 4) ni siquiera menciona la familia lingüística mataguaya (a no ser que esté erróneamente incorporada bajo otro rubro). Tampoco aparecen los wichí en el Cuadro II.9 del Atlas (López, 2009, p. 86, "Continuo linguodemográfico, según número de hablantes").

A pesar de sus limitaciones, el Atlas da cuenta de la diversidad irreducible que caracteriza el panorama lingüístico actual ${ }^{5}$. Dentro de ese panorama polígloto, el área geocultural chaqueña es relativamente poco diversificada (a diferencia de la desbordante exuberancia amazónica/orinoquiana). En lo que se refiere al Chaco Central, donde habitan los wichí, las familias lingüísticas mataguaya y guaycurú son las únicas presentes, geográficamente distribuidas en dos bloques contiguos: a grandes rasgos, la familia mataguaya ocupa el sector occidental (arribeño), y la familia guaycurú ocupa el sector oriental (abajeño).

En el capítulo IV del Atlas de la UNICEF, Marisa Censabella (2009) rectifica la antedicha omisión de la familia mataguaya, restituyéndola al mapa con sus cuatro lenguas integrantes: wichí, nivaclé, chorote y maká (pp. 151-152, Cuadro IV.2: "Familias lingüísticas y lenguas del Chaco y Oriente boliviano"). Al pueblo wichí -principal miembro de la familia- ella atribuye una población de "alrededor de 45.000", incluyendo a casi 2.000 wichí-autodenominados wehnayek- de la ribera norte del Pilcomayo boliviano ${ }^{6}$.

\footnotetext{
2 Jorge Suárez, Las lenguas indígenas mesoamericanas (1995), citado

3 En otra contribución al mismo volumen se lee que las familias lingüísticas precolombinas de América Latina "oscilarían entre 118 [...] y 140" (López, 2009, p. 80). En cuanto a "relaciones más amplias entre

${ }^{4}$ Ver el cuadro "Las familias lingüísticas en América Latina" de Sichra,

${ }^{5}$ Así y todo, problematiza la hipótesis paleoantropológica del origen beringiano de la población étnicamente preexistente de las Américas, portadora prehistóricamente de "una única lengua ancestral paleoamericana" (Encarta, 2008, "Lenguas aborígenes de Hispanoamérica").

6 Censabella, 2009, pp. 156 y 196 (Cuadro IV.14: "Pueblos indígenas en el Chaco y el Oriente bolivianos"). La autora se basa en estadísticas oficiales que "provienen del INDEC [www.indec.gov. ar/webcenso/ECPI/indicadores comparados.asp], con base en la ECPI [Encuesta Complementaria de Pueblos Indígenas] 2004-2005" (p. 159) -encuesta que, aclara ella, se realizó "sobre la base del Censo
}

El cálculo oficial de la población wichí total de las tres provincias argentinas de Salta, Formosa y Chaco arroja la cifra de 50.4197; y son unos 5 mil los wichí wehnayek quienes habitan el departamento de Tarija, Bolivia ${ }^{8}$.

Andrés Leake (2008, pp. 3-7) alerta sobre la precariedad de las estimaciones demográficas referidas a los pueblos étnicamente preexistentes del Chaco argentino ${ }^{9}$. Antes de inmiscuirnos en ese embrollo, vale decir que, sea cual fuere el cálculo más certero, los wichí conforman uno de los grupos lingüísticos más extensos de las tierras bajas del continente -con la particularidad diacrítica de que el $90,7 \%$ "habla habitualmente su propia lengua"10.

La familia lingüística guaycurú es aun más extensa y más numerosa. Los qom -etnia mayoritaria de la familia- según las estadísticas nacionales son un total de 69.452 personas (incluyendo a quienes comprende la primera infancia) ${ }^{11}$. Si se incluyen a los otros pueblos pertenecientes a las dos familias lingüísticas, la disparidad demográfica se torna aun más marcada. La familia guaycurú comprende a los pilagá y a los mocoví, sumando un total nacional para la familia de 89.754 individuos; la familia mataguaya, por su parte, comprende a los chorote y a los nivaclé, sumando un total nacional para la familia de $43.202^{12}$. Aun agregando los datos demográficos referidos a los pueblos de la familia mataguaya ubicados en el Chaco paraguayo -nivaclé, manjuy y maká- la disparidad no disminuye significativamente, sobre todo teniendo en cuenta que la

2001" (p. 161). El cálculo que hace la autora no está corroborado por sus propias precisiones, según las cuales los wichí que habitan las provincias argentinas de Chaco, Formosa y Salta suman 36.149 personas (de todas las edades), con otros 3.887 en el resto del país: o sea, un total de 40.036 (p. 160, Cuadro IV.3, "Población indígena en Argentina por región censal, área Chaco"). Según el mismo cuadro, el $34,6 \%$ de la población total wichí vive en zonas urbanas, cifra que en otro momento se cambia por el $27,4 \%$ (p. 166).

${ }^{7}$ Wallis, 2016, p. 27, citando el Censo Nacional de Población, Hogares y Viviendas 2010 (con el agregado de que, por su propia estimación, la población wichí del Chaco argentino ronda en los $60 \mathrm{mil}$ ). El 84\% de esa población está supeditado a las jurisdicciones de las provincias de Salta y de Formosa -en proporciones distribuidas equitativamente entre las dos- y el $16 \%$ restante pertenece jurisdiccionalmente a la provincia de Chaco.

${ }^{8}$ Alvarsson, 2012, pp. 58-59; Palmer, 2005, p. 13; Wallis, 2016, p. 27. Sobre los wichí wehnayek, ver Combès en este dossier.

${ }^{9}$ cf. Trinchero, 2000, p. 70 n. 26. Para datos demográficos de las etnias originarias del Chaco argentino, ver Montani, 2004, p. 25

${ }^{10}$ Wallis, 2016, p. 14, citando la ECPI 2004/2005 (sin diferenciación entre comunidades aisladas y urbanas). Censabella, 2009, p. 156 citando a Terraza, 2001, resalta un "quiebre de la transmisión intergeneracional en los alrededores de la localidad de Rivadavia, provincia de Salta", a raíz de que "factores socio-históricos específicos han provocado que, en los últimos treinta años, muchos padres jóvenes decidan no transmitir más la lengua originaria a sus hijos como primera lengua."

${ }^{11}$ Censabella, 2009, pp. 159-60 (Cuadro IV.3, "Población indígena en Argentina por región censal, área Chaco"). Del total, 47.591 viven en las provincias de Chaco, Formosa y Santa Fe; 14.466 habitan en la provincia y ciudad de Buenos Aires; y otros 4.779 se ubican en el resto del país. Según la autora, el $68,6 \%$ del total nacional vive en zonas urbanas.

12 Para el desglose de los datos demográficos respectivos, ver Censabella, 2009, p. 159-160 (Cuadro IV.3: "Población indígena en Argentina por región censal, área Chaco"). 
familia guaycurú cuenta también con el pueblo caduveo del Pantanal brasileño (el cual constituye una "pequeña porción correspondiente a la región Gran (haco") ${ }^{13}$.

Sin aventurarnos en el campo tupido de la relativa antigüedad en la región de las familias lingüísticas mataguaya y guaycurú, cabe remarcar las diferencias culturales notorias que ostentan los wichí y los qom, etnias numéricamente principales de las dos familias. Además de hablar lenguas pertenecientes a familias lingüísticas no claramente emparentadas entre sí, adoptaron históricamente -ante la invasión europea de sus territoriosestrategias divergentes. La mentada proclividad combativa de los qom contrasta con la apertura complaciente de los wichí. Corolario o no de esa divergencia, el hecho es que hoy en día, tal y como observa Rodrigo Montani, "el bilingüismo más extendido y hasta el monolingüismo español de los tobas contrasta con el bilingüismo menos extendido e incluso el monolingüismo wichí" (2017, p. 242).

Contemplados en su conjunto, los territorios wichí y qom, al centro de la ecorregión chaqueña, se perciben como un enclave al interior del cual las dos lenguas, resistentes entre sí, se han desenvuelto sin resistencia de parte de otras familias lingüísticas de la periferia. Como posible excepción se da el caso histórico de las familias a las que pertenecían las lenguas lule y vilela del Chaco austral, cuyos hablantes desaparecieron ante el avance del frente colonial desde el sur. ¿La dispersión de los lule hacia el norte habrá producido una hibridación con la lengua de los wichí de la cuenca del Bermejo?

De comprobarse tal hipótesis, concordaría con el hecho de que, como bien se sabe, la lengua wichí consiste en una cadena dialectal entre cuyos extremos sociogeográficos no hay comprensión mutua ${ }^{14}$. Esa proliferación dialectal apunta a procesos de fusión lingüística resultantes de relaciones interétnicas en el pasado prehispánico (si no, también, hispánico). Asimismo, evidencia el dinamismo de la lengua wichí, la que, en contextos de frontera interétnica, se hace valer (sin imponerse) y, a la vez, se adapta, hasta dar a luz a variantes híbridas que no dejan de ostentar su filiación wichí. Dicho dinamismo garantiza que sus hablantes se mantengan, epistemológicamente, en su propio mundo cognitivo, permitiendo así la propagación y perpetuación de su identidad cultural.

Para los pueblos americanos precolombinos, en general,

\footnotetext{
${ }^{13}$ Censabella, 2009, p. 148. Para los datos demográficos respectivos, pp. 184 (Cuadro IV.9: "Población indígena del Chaco paraguayo") y 191 (Cuadro IV.11: "El espectro lingüístico Mataco-Mataguayo"). Con respecto a los Caduveo: "En 1995 eran unos 1200 distribuidos en tres comunidades alrededor de la sierra de Bodoquena" (Wikipedia, "Caduveos", https://es.wikipedia.org/wiki/Caduveos).

${ }^{14}$ Braunstein, 1990; 1992; 2008, pp. 3-4. Para una síntesis exhaustiva de la historia del estudio de la lengua wichí, ver Montani 2017, pp. 122-132. Con respecto a la diversidad dialectal, el intérprete wichí que participó de oficio de un caso en la Cámara Criminal de Orán me contó que los wichí involucrados no lo entendían porque provenían de otra zona dialectal.
}

la "dinámica sociolingüística" está "marcada por un multilingüismo ancestral" (López, 2009, p. 78). Para el pueblo wichí, en particular, el bilingüismo siempre existió como producto de matrimonios interétnicos. Por ejemplo, cuando empezó la colonización de su territorio de la cuenca del río Pilcomayo, a principios del siglo $\mathrm{XX}$, el autodenominado "misionero de la conquista", Domingo Astrada, conoció a un joven de 24 años, de madre wichí y padre qom. Los qom, por su parte, contaban con un intérprete del idioma wichí (Astrada, 1906, pp. 109, 124).

Denominado zlahyenek en idioma wichí -término cuya raíz parece ser el vocablo zlahyi, 'boca' o 'idioma', y que se traduciría como '[él que está] hecho boca' (o sea, 'portavoz', o mouthpiece en inglés)- el intérprete se valora en el contexto cultural propio como facilitador de la comunicación interétnica, sin que su posición le aporte ningún prestigio ni autoridad ${ }^{15}$. Su rol utilitario se tornó palpable con la irrupción de la sociedad colonial. Colón se sirvió de cautivos que tomó entre los arahuacos caribeños -y a quienes, mediante "señas y meneos", comunicó su sed del oro- para que ellos transmitan esa sed a los habitantes. Cuatro siglos después, en el ámbito wichí, los patrones azucareros (entre otros) consiguieron mediante el "lenguaraz", como se lo designaba, la mano de obra que buscaban. Y al mismo lo remuneraban con un salario a la par de los así llamados "capitanes" (Montani, 2015, p. 28).

Hoy en día, si un/a wichí requiere la asistencia de un intérprete en la gestión que sea -administrativa o judicialdescubrirá que aquella persona otrora buscada se ha convertido en persona no grata. El porqué del cambio no es difícil de captar. Es que, para aquellos miembros de la sociedad nacional que necesitan los servicios de los wichí, el intérprete resulta ser una herramienta indispensable; pero, cuando la intervención del intérprete es a los efectos de acordarles a los wichí su libertad de expresión, se lo considera, por lo general, "innecesario". Además del inconveniente que implica para los representantes del Estado el despegarse de sus propios códigos lingüísticos, la participación de un intérprete implica cierta complejidad procesal.

El derecho a la asistencia de un intérprete es de raigambre constitucional ${ }^{16}$. A las personas que pertenecen a minorías étnicas, religiosas o lingüísticas, se les garantiza el derecho de "emplear su propio idioma" para "entender y hacerse entender", sin restricción alguna en cuanto al ámbito de su

\footnotetext{
${ }^{15}$ En el presente escrito, se refiere al intérprete wichí como persona masculina, pero la referencia no tiene connotaciones de género. De hecho, quien desempeña actualmente el cargo de intérprete oficial de la lengua wichí ante la Justicia salteña -Sandra Pisco- es una mujer chorote-wichí.

${ }^{16}$ En su art. 75, inc. 22, la Constitución Nacional incorpora el Pacto Internacional de Derechos Civiles y Políticos de la ONU y la Convención Americana sobre Derechos Humanos de la OEA ("Pacto de San José de Costa Rica"). Ambas normas versan sobre la garantía que asiste a toda persona que "no comprende o no habla el idioma empleado en el tribunal" (respectivamente: art. 14, inc. 3, apartado f, y art. 8, inc. 2a). Cf. también art. 20, inc. 2, de la Declaración de Barcelona sobre Derechos Lingüísticos (1996).
} 
uso $^{17}$. Tal como puntualiza el jurista Juan Manuel Salgado:

la norma constitucional que declara la preexistencia étnica y cultural [art. 75, inc. 17] [...] implica el reconocimiento del derecho a usar el propio idioma preexistente en todas las gestiones estatales (aun como testigos). Aunque los códigos procesales penales y los pactos de derechos humanos establecen la posibilidad de contar con intérprete para quienes no conocen el idioma, el derecho a utilizar la lengua materna[sic] no debe estar limitado por la "comprensión" del idioma oficial, ya que la cláusula constitucional y el principio de no discriminación implican que los miembros de pueblos indígenas deben poder expresarse con la misma soltura al hablar con que se manifiestan los ciudadanos no indígenas (2006, p. 141).

El procedimiento no admite vericuetos: más allá de la comprensión y el manejo del idioma tribunalicio que tenga la persona indígena, privarle del uso de su propia lengua le quita la libertad de expresión necesaria para su expresa manifestación de voluntad. La falta de intérprete deviene en un vicio formal que, como tal, acarrea la nulidad de lo actuado, porque vulnera los principios constitucionales de debido proceso y legítima defensa en juicio. Ni lo subsana la convicción subjetiva que tenga el actuario de que entiende al wichí, ni de que el wichí lo entiende a él ${ }^{18}$. En cuanto se la requiere, la asistencia de un intérprete es un derecho inclaudicable ${ }^{19}$.

Lo más común, no obstante, es que la participación de un perito intérprete-sobre todo, un intérprete de parte-sea sistemáticamente denegada. Su Señoría suele fundar su negativa en que "en la totalidad de los actos procesales llevados a cabo en sede judicial el imputado se expresó correctamente y no evidenció dificultad alguna para la comprensión del idioma [español]"20. En caso de un/a denunciante wichí que quisiera ratificar su denuncia a través de un intérprete, el magistrado le deniega la posibilidad, alegando que la denuncia se radicó sin intérprete ante la policía. Sin el respaldo de la ratificación, la denuncia termina desestimándose ${ }^{21}$.

\footnotetext{
17 Pacto Internacional de Derechos Civiles y Políticos de la ONU (art. 27). Cf. art. 12 del Convenio 169 de la OIT (ratificado por Ley Nacional No 24.071 y con depósito formal en Ginebra), y art. 13, inciso 2, de la Declaración de Naciones Unidas sobre los Derechos de los Pueblos Indígenas (2007), suscripta por el Estado argentino.

18 Previo a su modificación, el Código Procesal Penal de Salta (Ley 6.345/85) estipulaba en su art. 258 que "Se deberá nombrar intérprete aun cuando el juez tenga conocimiento personal de la lengua o del dialecto a interpretar".

${ }^{19}$ En la audiencia pública convocada por la Corte IDH en el caso Lhaka Honhat (14-15/03/19), los peticionarios mismos deben haber optado por declarar en el idioma de la Corte.

${ }^{20}$ Causa c/ Víctor Juárez s/ Abuso Sexual Calificado por Acceso Carnal en perjuicio de Darío Manuel González, Cámara del Crimen, Orán, Expediente 3.015/03, fs. 170.

${ }^{21}$ Una excepción notoria es el caso -de último momento y de público
}

La siguiente anécdota ilustra algunos de los entuertos que se presentan. Un Juzgado de Instrucción de la localidad salteña de Tartagal citó a un hombre wichí a prestar una "declaración testimonial" en una causa penal en la que no figuraba como la persona denunciada. Llegado el día de la audiencia, el wichí fue al Juzgado acompañado por quien escribe, en calidad de intérprete. Ante el pedido de autorización para la participación del intérprete, el Juez miró de reojo al hombre wichí, a quien no conocía, y fulminó: "Él sabe castellano. De todos modos, hay que hacer el pedido de intérprete por escrito y, en caso de que se acepte, el Juzgado oficiará al IPPIS [Instituto Provincial de los Pueblos Indígenas de Salta] para que nombren un intérprete". Al señor wichí lo hicieron entrar solo a la oficina del sumariante. Al rato salió, pávido, y le dijo al intérprete: “Dicen que entres. Hay una parte que no entiendo, algo de 'detención'". Juntos ingresamos a la oficina del sumariante, quien anunció con irritación que el señor wichí tenía dificultad con la lectura del acto de eximición de detención y que, por orden del Sr. Juez, hacía falta un intérprete para explicarle el significado del acto. Así trascendió que la supuesta "declaración testimonial" era una indagatoria y que el wichí declaraba en calidad de imputado. El intérprete le pidió al sumariante que leyera la declaración, lo que tuvo como respuesta: “Ud. está aquí para explicarle lo de la eximición de detención, nada más". Entre idas y venidas del Juez, le dieron vista de la declaración indagatoria al intérprete. Al escucharla traducida a su lengua, el imputado wichí dijo que no era lo que había querido decir. Entre otras idas y venidas del Juez, los errores de la declaración hecha sin la asistencia de intérprete fueron subsanados.

En aquel caso, el delito que se le imputaba al señor wichí era un delito excarcelable. Pero el incidente sirve para demostrar, no sólo la reticencia judicial para el reconocimiento de los derechos lingüísticos que asisten a personas pertenecientes a pueblos preexistentes, sino también el potencial peligro de que recaiga injustamente sobre esas personas una sentencia de culpabilidad cuando declaran sin intérprete. Hay casos en los que languidecen en la cárcel personas wichí para quienes o fue denegado el pedido de intérprete o no fue designado un intérprete de oficio. El peligro se ejemplifica con el caso de Qa'tu, un joven adulto wichí quien, mientras estaba detenido durante la etapa investigativa de su causa, fue sometido a un sorpresivo examen psicológico. Después de la entrevista, su Defensa la impugnó y solicitó la asistencia de un intérprete, pero la psicóloga rechazó sin más trámite el pedido, argumentando que había logrado que el joven wichí responda a las "preguntas sencillas" que ella le hizo. Además de la coerción que la denegatoria implica, también es abusivo reducir una entrevista a un intercambio de simplismos y privarle así al wichí de la sofisticación conceptual que maneja a través de su propio

conocimiento- de una menor wichí violada por ocho jóvenes criollos en banda. Con la asistencia de la intérprete wichí de oficio (ver nota 15), la víctima logró desagraviarse, por lo menos penalmente, con una sentencia de 17 años de cárcel para cada uno de sus abusadores adultos. 
idioma. Las consecuencias procesales son graves. En el caso de referencia, la psicóloga terminó diagnosticando que el preso wichí era "propenso a la mentira", evaluación peyorativa que el Juez tomó como elemento probatorio para fundamentar su procesamiento y encarcelamiento de Qa'tu²2.

La realidad es que, a excepción de algunos que tienen mejor incorporado el bilingüismo, la lengua de uso cotidiano es, para la enorme mayoría de los wichí justiciables, su propio idioma ancestral. La precaria escolaridad que hayan tenido, más un contacto ocasional con la sociedad colona, sólo les proporciona un dominio incipiente del idioma oficial. Hablan un dialecto wichí del castellano, con un léxico prestado a los "chaqueños" (colonos criollos), el que de por sí es un idioma distinto al del Juzgado y requiere la intervención de un intérprete. (De hecho, en una ocasión tuve que participar como intérprete en la declaración judicial que un dirigente wichí realizó en castellano).

No hay que suponer que la participación de un intérprete garantice que se haga lugar al derecho indígena. El uso de la lengua propia no conduce automáticamente a una respuesta favorable de parte del Estado. No se logró, por ejemplo, el sobreseimiento de Qa'tu, a pesar de que en el juicio pudo finalmente expresarse en su propio idioma wichí (después de siete años de "prisión preventiva" sin intérprete) y a pesar también de la incorporación en el expediente de peritajes antropológicos de Vito Márquez y de José Braunstein, pruebas contundentes de la inimputabilidad del acusado ${ }^{23}$.

El abogado kolla, Eulogio Frites, desde mucho antes de la reforma constitucional de 1994, siempre bregó por el recurso al peritaje lingüístico y antropológico para hacer traslucir la "cultura y cosmovisión" de personas encausadas que pertenecen a pueblos preexistentes (Frites 2011: 97). En su libro sobre el derecho de los pueblos indígenas, invoca dos causas en que personas wichí estuvieron acusadas de delitos penales. La primera fue un caso de infanticidio (filicidio) en la provincia de Formosa:

Desde el punto de vista penal, los wichí practican la eutanasia en casos extremos. En 1968, se ventiló el caso Peña, Santiago[,] quien ayudó a morir a su hija, "porque de todas maneras se iba a morir", diciendo que lo había hecho para aliviarle el sufrimiento. Para el derecho tradicional wichí esta conducta no es imputable, pero intervino el juez del crimen de Formosa y lo condenó a ocho años de prisión, aplicando la escala menor pero ningún eximente de pena. Aquí hubo un peritaje antropológico del Lic. Miguel N. [sic: léase H.] González,

\footnotetext{
${ }^{22}$ Para colmo, en la audiencia de juicio, el tribunal le informó al encartado wichí: "Ud. no está obligado a decir la verdad", invitándolo a incriminarse por incurrir en la mendacidad. Sobre el caso Qa'tu, ver Palmer, 2011.

${ }^{23}$ Para mantenerse en su tesitura condenatoria contra legem, el Tribunal a cargo cometió el delito de plagio (ver Petición ante la Comisión Interamericana de Derechos Humanos, Ref.: P-176-10 - José Fabián Ruiz).
}

basado en el derecho consuetudinario wichí y en la cosmovisión de este pueblo, pero los jueces mantuvieron sus ideas (Frites, 2011, p. 100) ${ }^{24}$.

La segunda causa fue un proceso oral y público realizado en idioma wichí, en 1987, ante la cámara en lo Criminal de Orán, Distrito Judicial del Norte de la Provincia de Salta (Frites, 2011, p. 164):

La Cámara de Apelaciones en lo Criminal de Orán trató el caso de la muerte del comerciante William Allen de nacionalidad siriolibanesa y norteamericana, dueño de un negocio de ramos generales y residente en Hito 1 de Tartagal.

El indígena wichí Adoro López era empleado de Allen y fue con dos amigos a pedir que le pagara con dinero -y no en especies- un trabajo realizado[,] porque quería comprar carne para un asado, hecho que molestó al comerciante al punto de agredir a López y éste se defendió con un golpe de puño haciéndolo caer al suelo y golpearse en un tronco.

Los tres wichí fueron condenados a 10 años de prisión por la muerte de Allen.

Desde la sentencia habían pasado ya dos años. El expediente era voluminoso en el tribunal de Orán [...]. Luego de examinar el sumario y la sentencia de primera instancia, comprobada la inexistencia de pruebas para condenar a los wichí, así como también la falta de peritajes lingüísticos y antropológicos, pedimos [...] la nulidad de lo actuado por no tener en cuenta el derecho indígena fundado en el art. 9 y concordantes del Convenio 107 de la Organización Internacional del Trabajo (OIT), aprobado y ratificado en 1959 por el Estado argentino con la ley 14.932[,] y el art. 18 de la Constitución Nacional. También solicitamos que el proceso, después de la anulación, sea efectuado en idioma wichí y español y se designara perito traductor por la defensa al indígena wichí don Melecio Zamora y[,] por la Fiscalía, al indígena wichí don Juan Mansilla. El tribunal hizo lugar a la anulación del proceso anterior y aceptó que el nuevo proceso de Cámara sea en idioma wichí-español con los peritos propuestos por la defensa y la fiscalía. Así fue que declararon en su idioma los tres implicados, se tomó testimonio a más de 30 testigos, se formalizó la acusación del fiscal y[,] formulada la defensa, el tribunal falló [...] declarando nulo el proceso de primera instancia y determinando que la muerte de Allen se había producido cuando cayó sobre un tronco en el momento que Adoro López[,] atacado por aquél[,] se defendió con un golpe de puño. El

\footnotetext{
${ }^{24}$ Sobre ese peritaje antropológico, ver González, 1968, 2010.
} 
tribunal expresó que se trataba de un delito preterintencional [sin dolo], por lo tanto[,] imputó a Adoro López y dejó libres de culpa y cargo a los demás (Frites, 2011, pp. 142-439).

Ambos casos ilustran el hecho de que, aun con aportes de peritos en defensa de imputados wichí, no se revierte la desigualdad entre el derecho consuetudinario indígena y el derecho romano (en términos de Frites, el "derecho positivo del Estado") ${ }^{25}$.

El derecho al uso de la lengua propia se hace exigible no sólo en la esfera judicial -del fuero que sea (penal o civil)-, sino en todo ámbito de la relación entre pueblos indígenas y el Estado donde estén afectados los intereses de aquéllos. En lo legislativo y lo administrativo, tanto como en lo judicial, corresponde que sean asistidos por un intérprete para que puedan entender y hacerse entender con respecto a temas atinentes, por ejemplo, la propiedad de la tierra, el medio ambiente, la salud, la educación, el Registro Civil. En el contexto de audiencias públicas referidas a desmontes, por ejemplo, no son equiparables la oposición pronunciada por un/a wichí en su propia lengua y aquélla formulada en el dialecto wichí del castellano -por más que la falta de impacto sobre los funcionarios de Medio Ambiente sea la misma.

Sigue latente el sustrato conflictivo con el que siempre estuvo marcada la relación entre el pueblo wichí y los miembros de la sociedad neocolonial ${ }^{26}$. En la actualidad, además, se nota una creciente judicialización de disputas intestinas. En la Circunscripción Tartagal del Distrito Judicial del Norte de la provincia de Salta, son relativamente frecuentes las causas que se tramitan en el ámbito del Juzgado de Violencia Familiar y de Género, emanadas de acusaciones de violencia de género en el seno de relaciones conyugales. Tampoco son desconocidas las denuncias por abuso sexual extraconyugal. Por otro lado, en los Juzgados de Familia se ventilan disputas sobre la tenencia de huérfanos, disputas en las que los contrincantes son

\footnotetext{
25 Frites (2011, p. 99) aduce también el caso mapuche de Lonco Luan, Neuquén, ocurrido en 1978 (en plena época de la dictadura militar) y resuelto favorablemente en 1985 (después de reinstaurada la democracia), tras una apelación contra una condena de primera instancia. Teniendo en cuenta el idioma y las pautas culturales de los protagonistas mapuche, el tribunal resolvió que no tuvieron conciencia de la criminalidad de sus actos.

${ }^{26}$ Montani (2017, p. 110 n. 28) anota cuatro casos de homicidio entre ambas poblaciones en el territorio wichí del ejido municipal del pueblo de Coronel J. Solá (departamento Rivadavia, Salta): i) la muerte de un wichí a manos de varios criollos; ii) la muerte de un criollo por un wichí criado entre criollos; iii) la muerte de una criolla por un wichí; iv) la muerte de éste último a manos de un policía criollo. Hace casi 50 años, Bartolomé (antropólogo argentino radicado en México) diagnosticó el sesgo racista que subyace a la operación de la justicia en el ámbito chaqueño: "Tanto los gendarmes como los policías protegen a los criollos y extranjeros en detrimento de los indígenas. No son extraños los casos de homicidios en los que el culpable no es castigado, ya que la víctima es un indio (Fock 1966/67). Por lo común, estos sucesos se producen como resultado del conflicto existente entre ganaderos e indígenas: los aborígenes, llevados por el hambre [y la bronca], suelen cazar los animales de los ganaderos que invaden sus tierras [léase: chacras], provocando la reacción [homicida] de éstos" (1972, p. 317).
}

integrantes de las parentelas matrilateral y patrilateral de los huérfanos. Y, en el mismo ámbito judicial, se les quita la tenencia de sus hij@s a madres declaradas incompetentes para el cuidado de su propia progenie -frecuentemente, por estar presas de trastornos provocados por la cultura de la sociedad envolvente, como el alcoholismo y la drogadicción. En un caso reciente (2018), se suicidó una madre wichí -"menor" en términos del derecho oficialcuyos hijos habían sido institucionalizados con miras a que sean declarados adoptables.

El auge de la intervención del Estado al interior de la sociedad wichí -de oficio o a instancias de los wichí mismos- refleja, por un lado, la intensificación del conflicto interno y, por otro lado, la pérdida de jurisdicción propia (o sea, la pérdida de la posibilidad de resolver problemas autónomamente), síntomas en ambos casos del impacto etnocida de la colonización ${ }^{27}$. Generalmente los expedientes no son de público conocimiento y se tramitan a puertas cerradas, razón por la cual se desconoce todo lo relativo a la intervención de peritos intérpretes. Aun suponiendo que fuese autorizada, el problema para el intérprete en disputas intestinas es el de mantener una posición neutra para evitar acusaciones de parcialismo por alguna de las partes. Según un intérprete mocoví de la provincia de Chaco, Roberto Manito, la adopción de una posición neutra se logra por medio de una consulta con todos los allegados de las personas involucradas. Alternativamente, nada obsta a que sean varios los intérpretes que intervengan, como en el caso de una demanda laboral incoada por tres wichí contra sus empleadores finqueros, donde las declaraciones de los testigos wichí fueron acompañadas por tres intérpretes: aquél nombrado de oficio por el Juzgado y dos más nombrados por las partes.

Siguiendo el ejemplo de José Braunstein (2010), la preponderancia de la operación de la Justicia estatal en la realidad wichí contemporánea merece un estudio antropológico-jurídico amplio, a los fines de lograr una mayor comprensión de los derechos en litigio.

En la Provincia de Chaco, ha habido avances legislativos en materia de lenguas indígenas. En 2011, los idiomas qom, moqoit (de la etnia mocoví) y wichí se declararon lenguas oficiales (Ley provincial 6604) ${ }^{28}$. Y en 2014, con el objeto de generar "condiciones de accesibilidad y equidad en el trato", se creó la carrera universitaria de traductoresinterpretes de esas tres lenguas (Ley provincial 7516) ${ }^{29}$.

En la Provincia de Salta, el Consejo de la Lengua Wichí presentó últimamente (2018) un proyecto para la formación de intérpretes bilingües wichí. Siguiendo el modelo chaqueño, propone la oficialización de la lengua wichí y la creación de una carrera de dos años -con certificación de la Universidad Nacional de Salta (UNSa)-

\footnotetext{
27 Sobre la resolución consuetudinaria de "conflictos intra-aldeanos", con referencia específica a una "grave pelea" sucedida en 2006 en la aldea de Los Baldes, ver Montani, 2017, pp. 170-171.

28 https://es.wikipedia.org/wiki/Provincia_del_Chaco

${ }^{29}$ http://www.eschaco.com/vernota.asp?id_noticia=24897
} 
que faculte a los/as egresados/as para actuar en todos los estrados judiciales y reparticiones administrativas.

Entre los contenidos de la carrera chaqueña, se presta atención a "las técnicas de traducción e interpretación". Enfrenta así el desafío semántico de "trasladar el lenguaje jurídico al lenguaje utilizado por los pueblos originarios" 30 . En el caso wichí, la conversión del idioma a quo al idioma ad quem implica no sólo la sustitución léxica de conceptos técnicos (los cuales requieren una perífrasis explicativa más o menos extensa para rendirlos inteligibles), sino también la dilucidación de una filosofía del derecho culturalmente sui generis que se basa en un sistema de valores incompatible e, incluso, opuesto al de la sociedad receptora. A modo de ejemplo, los wichí invierten la atribución de responsabilidad penal en casos de homicidio: la muerte premeditada se justifica (por estar motivada), y la muerte "pasional" se condena (por carecer de motivo racional) (Palmer, 2005, p. 154).

Ese desafío semántico se ilustra con el ejemplo de los letreros de la Ciudad Judicial de Tartagal, donde los nombres de las distintas dependencias están traducidos al wichí (ver Tabla 1) ${ }^{31}$. Cabe decir, de entrada, que los letreros son nombres y, como tales, intraducibles, sino mediante la perífrasis. Un rasgo diagnóstico de los giros perifrásticos utilizados es el uso reiterado de la frase wichi lat'es ihi(che), 'culpable(s) [de alguna acción contraria a la norma]'. Aparece en la traducción de los letreros de cada uno de los juzgados penales y correccionales:

- el Tribunal (o Sala) de Juicio, al igual que el Juzgado de Garantías, es donde 'se estudian [casos de] quienes son culpables' (n'otetsan n'oñaj tä lat'es ihiche)-traducción que debe entenderse en el sentido de que el juzgado arbitra en casos de personas que tienen causas;

- el Juzgado Correccional y de Menores 'examina [casos de] jóvenes culpables' (i'tetsan n'atses ta lat'es ihiche) -traducción sujeta al mismo comentario que la anterior: o sea, debe entenderse en términos de que el juzgado en cuestión arbitra en casos de jóvenes que tienen causas.

\footnotetext{
30 Dictamen del Superior Tribunal de Justicia de la provincia de Chaco, de fecha 08/10/14, sobre el proyecto de la ley que luego fue sancionada como ley provincial 7516/14.

31 La Ciudad Judicial de Tartagal, edificio compuesto de una planta baja y tres pisos, se inauguró en 2015. Únicamente se tradujeron los letreros de las dependencias del poder judicial, dejando sin traducir los de las reparticiones del ministerio público, como por ejemplo las fiscalías y las defensorías oficiales. En la tabla 1 se alistan los juzgados penales y civiles - y oficinas conexas, dejando de lado oficinas auxiliares ("Servicio Médico-Asistentes Sociales-Psicología") y administrativas ("Mesa Distribuidora", "Ujiería", "Archivo Repositorio"), como también -por no estar directamente involucrada en la tramitación de causas- la Escuela de la Magistratura. Tampoco se incluye en el cuadro el sector de servicios internos ("Biblioteca", "Enfermería", "Prensa", "Correo Externo", "Mantenimiento Edilicio", "Servicios Generales"), porque la traducción al wichí de sus letreros no implica conceptos de derecho. El Juzgado de Violencia Familiar y de Género se creó después de la inauguración del edificio, razón por la cual su letrero no cuenta con una traducción al wichí.
}

En el ámbito civil, el Juzgado de Personas y Familia es donde 'se examina la culpa de un solo individuo' (n'otetsan n'oelh wuñalha lat'es). La culpabilidad atribuida es la misma que en casos de responsabilidad penal -con la diferencia de que aquí la traducción acusa un enfoque individualista excepcional (sin antecedente ni resabios en ningún otro momento).

La aludida atribución anticipada de culpabilidad es del mismo grado de convicción que en casos resueltos -tanto aquéllos que obran en la oficina de "AdministraciónRecursos Humanos", donde 'se estudia y se clasifica la culpa de la gente' (i'tetsan wet ikanchä wichi lates), como aquéllos ubicados en la Secretaría de Detenidos, donde 'se estudia la culpa de la gente y [de] los presos' (itetsan wichi lat'es wet iñaj tä n'ophohiche).

El único letrero que relativiza la carga de culpabilidad es el de la UER (Unidad de Expedición y Recepción de antecedentes penales, dependencia del Registro Nacional de Reincidencia). La traducción del acrónimo -'se ocupa de estudiar si una persona es culpable o no lo es' (yen chumet'a ta itetsan n'oelh chik lat'es ihi wok naj latesä)es inexacta, ya que la oficina en cuestión se ocupa de averiguar si una persona tiene antecedentes, pero deja en claro que una persona no siempre es culpable de lo de que esté acusada.

La atribución anticipada de responsabilidad penal da la pauta de que una persona acusada es culpable hasta que compruebe su inocencia. Dicho sesgo perjudicial subvierte el sagrado principio del derecho romano (in dubio pro reo) según el cual, supuestamente, toda persona es inocente mientras no se compruebe su culpabilidad. ¿De dónde viene la equivalencia -implícita en las traducciones citadasentre "tener una causa" y "tener la culpa"? El derecho wichí, por su parte, reconoce distintas gradaciones de culpabilidad, las que distinguen entre la acusación (notiyej noelh lětes), la falsa acusación (nosujqanyaj) y la afirmación de responsabilidad (lětes ihi) ${ }^{32}$. Al borrar esa escala de gradaciones, las traducciones transmiten una percepción del sistema judicial oficial que acentúa el carácter punitivo del mismo en su relación con el pueblo wichí.

Al respecto, hay que destacar que, por lo visto, lo que el traductor volcaba a su propio idioma no fueron los nombres de las distintas reparticiones judiciales -los cuales, como ya se dijo, son intraducibles-, sino explicaciones que le fueran dadas acerca de las esferas de competencia de las mismas. O sea, traducía información suministrada por un informante hispanohablante. Al no estar disponible esa información previa, no se sabe en qué medida hubo un problema de comunicación y/o de comprensión entre el informante y el traductor. El caveat es pertinente en relación con otros letreros cuya traducción wichí es observable:

\footnotetext{
32 Conexamente, es pertinente la expresión wichí de causalidad explícita en los conceptos tamenej ('causar [que algo ocurra]') y mehyenej ('atribuir [a algo/alguien] la causa [de algo ocurrido]').
} 
Tabla 1: Letreros de la Ciudad Judicial de Tartagal (provincia de Salta). Las transcripciones de las traducciones al wichí son textuales. Suscitan cuestiones ortográficas y de puntuación que no se tratan por ser secundarias al aspecto semántico aquí priorizado. No obstante, dan lugar a la pregunta: ¿quién transcribe las declaraciones realizadas en lengua indígena? Antes de nada, tales declaraciones tienen que estar grabadas.

Table 1: Signposts of the Tartagal Judiciary Centre (Salta province). The transcriptions of the Wichi translations are verbatim. They raise spelling and punctuation issues that are not addressed because they are secondary to the semantic aspect prioritized here. Nevertheless, they give rise to the question: who transcribes the statements made in the indigenous language? First of all, such statements must be recorded.

\begin{tabular}{|c|c|c|}
\hline LETRERO & TRADUCCIÓN WICHÍ & $\begin{array}{l}\text { RETROTRADUCCIÓN (del wichí al } \\
\text { castellano) }\end{array}$ \\
\hline Tribunal de Juicio Sala 1 & $\begin{array}{l}\text { Lhipn'a hap'e Ihip ta n'otetsan } \\
\text { n'oñaj tä lat'es ihiche }\end{array}$ & $\begin{array}{l}\text { 'Aquí se examinan [casos de] quienes } \\
\text { son culpables' }\end{array}$ \\
\hline Sala de Juicios & $\begin{array}{l}\text { Lhip ta itetsan wichi tä lat'es } \\
\text { ihiche }\end{array}$ & $\begin{array}{l}\text { 'Es donde se examinan [casos de] } \\
\text { personas culpables' }\end{array}$ \\
\hline Juzgado de Garantías No 1 & $\begin{array}{l}\text { Lhip'n'ä hap'e lhip ta otetsan, } \\
\text { iñaj tä lat'es ihiche }\end{array}$ & $\begin{array}{l}\text { 'Aquí se examinan [casos de] quienes } \\
\text { son culpables' }\end{array}$ \\
\hline Juzgado de Garantías Nº 2 & $\begin{array}{l}\text { Lhipn'a hap'e Ihip tä otetsan, } \\
\text { iñaj tä lat'es ihiche }\end{array}$ & $\begin{array}{l}\text { 'Aquí se examinan [casos de] quienes } \\
\text { son culpables' }\end{array}$ \\
\hline $\begin{array}{l}\text { Juzgado Correccional y de } \\
\text { Menores }\end{array}$ & $\begin{array}{l}\text { Hap tä i'tetsan n'atses ta lat'es } \\
\text { ihiche }\end{array}$ & $\begin{array}{l}\text { 'Examina [casos de] jóvenes que son } \\
\text { culpables' }\end{array}$ \\
\hline $\begin{array}{l}\text { Juzgado de Personas y } \\
\text { Familia N } N^{\circ} 1\end{array}$ & $\begin{array}{l}\text { Lhip tá n'otetsan n'oelh } \\
\text { wuñalha lat'es }\end{array}$ & $\begin{array}{l}\text { 'Aquí se examina la culpa de un solo } \\
\text { individuo' }\end{array}$ \\
\hline $\begin{array}{l}\text { Juzgado de Personas y } \\
\text { Familia } N^{\circ} 2\end{array}$ & $\begin{array}{l}\text { Lhip ta n'otetsan n oelh } \\
\text { wañalha lät'es }\end{array}$ & $\begin{array}{l}\text { 'Aquí se examina la culpa de un solo } \\
\text { individuo' }\end{array}$ \\
\hline Juzgado Civil y Comercial & Itetsan wichi tä n'o tujlhayeh'en & $\begin{array}{l}\text { 'Examina [casos de] personas } \\
\text { endeudadas' }\end{array}$ \\
\hline Juzgado de Trabajo & $\begin{array}{l}\text { Itetsan hap wichil tä Iha'ilanep'e } \\
\text { mañay }\end{array}$ & $\begin{array}{l}\text { 'Examina [casos de] personas quienes } \\
\text { se pelean por cosas' }\end{array}$ \\
\hline Secretaría de Mediación & $\begin{array}{l}\text { Tä itetsan Ihip tä yamt'ilak } \\
\text { n'ewache mak tä ni-isa } \\
\text { yowoy'e[sic] }\end{array}$ & $\begin{array}{l}\text { 'Hace un estudio para evitar } \\
\text { transgresiones' }\end{array}$ \\
\hline UER & $\begin{array}{l}\text { Hap tä yen chumet'a ta itetsan } \\
\text { n'oelh chik lat'es ihi wok naj } \\
\text { latesä }\end{array}$ & $\begin{array}{l}\text { 'Se ocupa de estudiar si una persona } \\
\text { es culpable o no lo es' }\end{array}$ \\
\hline Secretaría de Detenidos & $\begin{array}{l}\text { Hap'e tä itetsan wichi lat'es wet } \\
\text { iñaj tä n'ophohiche }\end{array}$ & $\begin{array}{l}\text { 'Se estudia la culpa de la gente y [de] } \\
\text { los presos' }\end{array}$ \\
\hline $\begin{array}{l}\text { Administración-Recursos } \\
\text { Humanos }\end{array}$ & $\begin{array}{l}\text { Lhip ta i'tetsan wet ikanchä } \\
\text { wichi lates }\end{array}$ & $\begin{array}{l}\text { 'Se estudia y se clasifica la culpa de la } \\
\text { gente' }\end{array}$ \\
\hline
\end{tabular}

- la Secretaría de Mediación 'hace un estudio para evitar transgresiones' (itetsan Ihip tä yamt'ilak n'ewache mak tä ni-isa yowoy'e[sic]). Indudablemente, la traducción condensa una explicación más extensa;

- el Juzgado Civil y Comercial 'examina [casos de] personas endeudadas' (itetsan wichi tä n'o tujlhayeh'en) -seguramente, como en el ejemplo anterior, una versión sintética del original;

- el Juzgado de Trabajo 'examina [casos de] quienes se pelean por cosas' (itetsan hap wichil tä Iha'ilanep'e mañay)-formulación que se adecuaría más al ámbito del Juzgado Civil y Comercial que a controversias laborales.
Donde más se torna problemática la traducción wichí de un letrero es en la primera oficina con la que se topa al entrar al edificio. Es la oficina de "Informes", cuyo letrero se traduce como Tayotneh. La raíz del lexema (yotneh) se asemeja a la voz bermejeña yetnej, la que, según Lunt (2016, p. 112), significa 'nombrar' (equivalente al wuntej del wichí pilcomayense). Pero la traducción de "Informes" como el lugar donde 'se nombra [a alguien o algo]' implica un desfasaje insuperable entre el mensaje transmitido por el informante y su comprensión por parte del traductor. Para mayor confusión, la oficina en cuestión cambió últimamente de función y opera ahora bajo el rubro "Caja de Seguridad". No obstante, la traducción wichí sigue siendo Tayotneh, evidenciando lo retórico que fue el interés profesado en 
un primer momento por el Poder Judicial de Salta en que su centro de operaciones en el Distrito Judicial del Norte, Circunscripción Tartagal, sea un ámbito verdaderamente bilingüe. (Sobre el particular, cabe remarcar que el énfasis bermejeño de las traducciones dificulta su lectura para los wichí que no manejan ese dialecto -y quienes, a ojo, deben conformar por lo menos la mitad de la población wichí que acude al lugar.)

Un documento clave en relación con la traducción wichí de principios de derecho indígena consagrados en la normativa vigente es la cartilla bilingüe de Fundapaz, Derechos indígenas: acceso a las tierras y los territorios $(2011)^{33}$. Sin entrar aquí en un análisis pormenorizado del meritorio trabajo interpretativo realizado por los dos traductores wichí-Eduardo Pérez y Gerardo Juárez, quienes volcaron a sus respectivos dialectos el texto del abogado Jorge Tejerina- un par de ejemplos ilustra la complejidad de la tarea. Por un lado, el concepto mismo de "derechos indígenas" se glosa como 'lo de que corresponde que la gente no criolla disponga' (mak ta t'ahawetej ta iyej wichí ta ka hopeya siwel lhayis), frase perifrástica que lo único que aporta es un aval incondicional a la discriminación positiva a favor de los pueblos indígenas. Por otro lado, el vocablo "leyes" -igualmente propio del discurso jurídico "occidental" (y aun más prolífico)- queda sin traducir, quizás por ser infranqueable la brecha entre el dogmatismo legalista de ese discurso y la justicia consuetudinaria wichí, la que privilegia una flexibilidad condicionada por acuerdos pragmáticos entre las partes ${ }^{34}$.

Tanto los letreros como la cartilla son traducciones en forma escrita que desdibujan la distinción que se hace corrientemente entre interpretar y traducir (según la cual el trabajo del traductor tiene que ver con textos escritos, mientras el intérprete interviene en contextos orales). El intérprete traduce (acto seguido y de viva voz), y el traductor también interpreta. Tal lo expresado por Serafina Galeano, maestra bilingüe wichí de Ingeniero Juárez (provincia de Formosa) citada por el sacerdote Patricio Doyle (2003, pp. 166-167):

lo principal que nos afecta a todos nosotros, hasta los mayores, hasta los dirigentes, [es que] muchas veces no entendemos bien el castellano, y por ahí nos cuesta entender el escrito. O

\footnotetext{
33 La cartilla comenta la siguiente normativa: Declaración de la ONU (2007); Convenio 169 de la OIT (1989); art. 75, inc. 17, de la Constitución Nacional (1994); art. 15 de la Constitución de la provincia de Salta (1998); y Ley Nacional 26.160/2006.

${ }^{34}$ La justicia wichí se evidencia en la clausura de un partido de hockey evocado hace unos 50 años por Niels Fock: "A veces [... Tokwaj] creaba hostilidad entre los oponentes [...]. Finalmente la cancha podía terminar llena de cadáveres y los ganadores podían cortar la cabeza de sus enemigos y llevarlas a casa como trofeos. [...] Un padre o una madre [de los vencidos] podía pedir una compensación por el hijo asesinado, y todos los que hacían esa demanda eran compensados con collares de concha o con una cabra o con otra cosa valiosa. Cuando todas las demandas estaban arregladas, la gente dejaba de ser enemiga y una vez más eran buenos amigos. Cualquiera que hubiese tomado parte de una pelea estaba dispuesto a pagar" (en Montani 2017, p. 158, citando a Wilbert \& Simoneau Eds., 1982, pp. 123-125).
}

si explica en castellano por ahí nos cuesta entender. Por ejemplo, yo estudié en secundario. Para entender bien todo lo que me enseñaron, primero debo estudiar en castellano. Y luego volver a estudiar otra vez, en mi idioma: pensar a la vez en los dos idiomas. Y recién poder decir: "ah, esto dice tal cosa". En castellano dice tal cosa, y en el idioma nuestro wichí. Eso lleva mucho tiempo. Hay cosas que no puedo pensar en castellano al instante. Por ahí me preguntan cosas para responder en ese momento, pero me cuesta decir: "ah, sí...". Primero debo pensar un rato. Después recién decir sí o no. Ese es el problema de nosotros en cuanto a la lengua.

O sea, la interpretación es un paso previo a la traducción.

Lo que tiene de particular la interpretación wichí es su modus operandi. Al respecto, es pertinente la cita que hace el mismo sacerdote a Mario Mariño, obispo anglicano wichí, quien plantea que, para entender cómo otros hablan, hay que "sabe[r] muy bien interiormente lo que piensan ellos" (en Doyle, 2003, p. 184) ${ }^{35}$. La inferencia es que todo wichí -sea intérprete, traductor, bilingüe o 'cualquiera' (ezl chik hāpe)- busca el "interior" de las palabras: es decir, las sondea en busca del husék (buena voluntad wichí) que contengan (o no). Conviene traer a colación al respecto que, para los wichí, el cometido esencial del uso de la palabra es la expresión del husék. Así, Montani (2017, p. 414) deja sentado que "la palabra [...] es la manifestación más inmediata del lëhusek de una persona"36. El profundo vínculo que los wichí priorizan entre la palabra hablada y la transmisión de la buena voluntad denota un subliminal compromiso con la no violencia que, por constituir el principio rector de su identidad cultural, es irrenunciable -a pesar de que, por lo general, se los ningunea como si fuesen intrusos en las tierras por las que se desplazan, persiguiendo derechos quiméricos.

\section{Agradecimientos}

El presente texto combina versiones retocadas de dos ponencias: aquélla presentada en el Seminario-laboratorio "Exploraciones antropológico-lingüísticas entre los wichis del Gran Chaco" (Córdoba, 4-5 de junio de 2018) y otra, titulada "El intérprete wichí ante la Justicia salteña", presentada en el II Congreso de las Lenguas (Buenos Aires, 18-21 de julio de 2007) y en el IV Encuentro Nacional de

\footnotetext{
35 El psicólogo ruso Vygotsky (1896-1934) fue partidario de la separación analítica entre la palabra y el pensamiento: "para entender el habla del otro no es suficiente entender sus palabras: debemos entender su pensamiento" (en Buliubasich, 2019, p. 12). El planteo de Vygotsky es equiparable con el del obispo wichí en la medida en que el "pensamiento" que se transmite a través de la palabra se entienda como la buena voluntad wichí (husék) que, por su presencia o ausencia, se deja traslucir por ese medio.

${ }^{36}$ Cf. Palmer 2005, pp. 200, 211. Algo parecido se discierne en lo manifestado en la Cumbre Mundial de la Sociedad de la Información realizada en Ginebra en el año 2003, donde se declaró que "la comunicación tiene como fundamento una ética y una espiritualidad en el que los contenidos, los sentimientos y los valores son esenciales en la comunicación" (Pleguezuelos et al., 2017, p. 100).
} 
la Defensa Pública (Corrientes, 8-10 de agosto de 2007). A José Braunstein y a Rodrigo Montani-organizadores de dichos eventos- les agradezco el desinteresado apoyo que me brindaron en todo momento. Agradezco también a los responsables de la presente edición-Rodrigo Montani y Zelda Franceschi- sus minuciosos comentarios sobre una versión preliminar del presente texto.

\section{Referencias bibliográficas}

Aasen, B. (2009). Presentación. En: Atlas Sociolingüístico de Pueblos Indigenas en América Latina. UNICEF (pp. vii-ix). Cochabamba: FUNPROIEB ANDES.

Alvarsson, J.-Å. (2012). Etnografía 'Weenhayek. Campear y Pescar: La organización socio-económica y política, tomo 1. Uppsala: Universidad de Uppsala DiCA, 11.

Astrada, D. (1906). Expedición al Pilcomayo. Buenos Aires: Establecimiento Gráfico Robles y Cía.

Bartolomé, M. A. (1972). La situación de los indígenas en la Argentina: área chaqueña y provincia de Misiones. En Grünberg, G. (Ed.), La situación del indígena en América del Sur: Aportes al estudio de la fricción inter-étnica en los indios no-andinos (pp. 309-352). Montevideo: Tierra Nueva.

Braunstein, J. A. (2010) Tres problemas para el estudio del derecho usual entre los pueblos del Gran Chaco. Hacia una nueva carta étnica del Gran Chaco, 7, 7-10.

Braunstein, J. A. (1990). Tribus de los matacos. Hacia una nueva carta étnica del Gran Chaco, 1, 1-8

Braunstein, J. A. (1992). Esquema provisorio de las tribus chaqueñas. En Hacia una nueva carta étnica del Gran Chaco, 4, 2-3

Braunstein, J. A. (2008). Carta provisoria de las tribus wichí. En Hacia una nueva carta étnica del Gran Chaco, 8, 3-4.

Buliubasich, C. (2019). Prólogo. En Pérez, E., \& Wallis, C., (Eds.). Gramática wichi-Dialecto de Santa María, Salta (pp. 11-12). Salta: SMA Ediciones

Cámara del Crimen, Orán, Expte 3.015/03: causa c/ Víctor Juárez s/ Abuso Sexual Calificado por Acceso Carnal en perjuicio de Darío Manuel González.

Censabella, M. (2009). Chaco ampliado. En Atlas Sociolingüístico de Pueblos Indígenas en América Latina. UNICEF. Cochabamba: FUNPROIEB ANDES, (pp. 142-169)

Comisión Interamericana de Derechos Humanos, Ref.: P-17610 - José Fabián Ruiz.

Doyle, P. (2003). Mario Mariño, wichí y obispos: luz en las tinieblas y alboradas del mundo wichí (mataco) de Formosa. Resistencia: Librería de la Paz.

ENCARTA 2008. Enciclopedia Encarta, Microsoft Corporation 2007 (versión en formato CD): "Indígenas americanos"; "Lenguas aborígenes de Hispanoamérica"

Frites, E. (2011). El derecho de los pueblos indígenas. Buenos Aires: Programa de Naciones Unidas para el Desarrollo

FUNDAPAZ (2011). Derechos indígenas: acceso a las tierras y los territorios. Salta: Fundapaz.
González, M. H. (1968). Peritaje jurídico en un caso de filicidio. América indígena, 28(4), 907-918.

González, M. H. (2010). Filicidio. Hacia una nueva carta étnica del Gran Chaco, 7, 95-100.

Hernández de León Portilla, A. (2004). Las lenguas y escrituras mesoaméricanas. Arqueología mexicana, 70, 20-25.

Leake, A. (Ed.). (2008). Los pueblos indigenas cazadoresrecolectores del Chaco salteño: población, economía y tierras. Salta: Fundación Asociana.

López, L. E. (2009). Pueblos, culturas y lenguas indígenas en América Latina. En Atlas Sociolingüístico de Pueblos Indígenas en América Latina, UNICEF (pp. 21-99). Cochabamba: FUNPROIEB ANDES.

Lunt, R. (2016). Diccionario de la lengua wichí: Wichí-Español. Buenos Aires: Sociedad Bíblica Argentina.

Montani, R. (2004). Categorías materiales y formas sociales entre los wichís de Los Baldes (Salta, Argentina). Tesis de licenciatura, Universidad Nacional de Rosario.

Montani, R., (2015). El ingenio como superartefacto: notas para una etnografía histórica de la cultura material wichí. En Córdoba, L., Bossert, F., Richard N., (Eds.). Capitalismo en las selvas: enclaves industriales en el Chaco y Amazonía indígenas (1850-1950) (pp. 19-44). San Pedro de Atacama: Ediciones del Desierto.

Montani, R., (2017). El mundo de las cosas entre los wichís del Gran Chaco: un estudio etnolingüístico. Cochabamba: Itinerarios.

Palmer, J.H., (2005). La buena voluntad wichí: una espiritualidad indígena. Las Lomitas: Grupo de Trabajo Ruta 81.

Palmer, J. H., (2011). Justiciabilidad indígena en los tribunales salteños". En Braunstein, J. (Ed.), Etnología y Derechos Indígenas II (pp. 19-45). Fascículo 107 del Instituto de Investigación y Desarrollo. Buenos Aires: Academia Nacional de Ciencias de Buenos Aires.

Pleguezuelos, C. Klein, N.M., Romano, R., (2017). Desarrollo territorial y comunicación. En Lizondo, L., Pleguezelos, C. (Eds.), Vivencias y experiencias de comunicación comunitaria en el norte salteño (pp. 93-103). Salta: Universidad Nacional de Salta.

Salgado J. M., (2006). Convenio 169 de la OIT sobre Pueblos Indígenas (comentado y anotado). Neuquén: Universidad Nacional del Comahue.

Sichra I., (2009). Introducción. En: Atlas Sociolingüístico de Pueblos Indígenas en América Latina. UNICEF (pp. 3-17). Cochabamba: FUNPROIEB ANDES.

Trinchero, H. H. (2000). Los dominios del demonio: civilización y barbarie en las fronteras de la Nación - el Chaco Central. Buenos Aires: EUDEBA.

UNICEF 2009. Atlas sociolingüístico de Pueblos Indígenas en América Latina. Cochabamba: FUNPROEIB Andes.

Wallis, C. (2016). Iguales pero diferentes: uniendo lo propio con lo ajeno - el pueblo wichí en la actualidad. En Hirsch, S. \& Lazzari, A. (Dirs.), Pueblos indígenas en la Argentina: historias, culturas, lenguas y educación, tomo 4. (pp. 7-50). Buenos Aires: Ministerio de Educación y Deportes de la Nación. 